\title{
Período Crítico de InTERferênCIA de Euphorbia heterophylla NA Cultura da Soj a sob Baixa Densidade de Semeadura ${ }^{1}$
}

\author{
Critical Period of Interference of Euphorbia heterophylla in Soybean Crop under Low \\ Seeding Rate
}

MESCHEDE, D.K. ${ }^{2}$, OLIVEIRA JR., R.S. ${ }^{3}$, CONSTANTIN, J. ${ }^{3}$ e SCAPIM, C.A. ${ }^{3}$

\begin{abstract}
RESUMO - Durante o ano agrícola de 1999/2000, dois experimentos foram conduzidos na Fazenda Boa Terra, em Quarto Centenário-PR, com o objetivo de avaliar o efeito de diferentes períodos de controle e convivência de Euphorbia heterophylla sobre a produtividade da soja, cv. BRS-133, cultivada em baixa densidade de semeadura. Os períodos de convivência consistiram em manter a cultura na presença e ausência de E. heterophylla por 5, 12, 19, 26, $33,40,47,54,61$ e 68 dias após a emergência (DAE) e pelo ciclo todo. Guando da primeira capina, nos tratamentos mantidos em convivência por períodos iniciais com a comunidade infestante, e na colheita, nos tratamentos mantidos por periodos iniciais na ausência de plantas daninhas, foram determinadas as densidades e biomassas de E. heterophylla. A presença da infestante proporcionou perdas diárias de produtividade de $5,15 \mathrm{~kg} \mathrm{ha}^{-1}$, ao passo que a ausência até $44 \mathrm{DAE}$ representou ganho diário de produtividade de $7,27 \mathrm{~kg} \mathrm{ha}^{-1}$. Verificou-se que a convivência da soja com $E$. heterophylla por até 17 dias após a emergência não causou qualquer efeito sobre a produtividade, enquanto o período total de prevenção da interferência foi de 44 dias após a emergência, o que configura um período crítico de competição dos 17 aos 44 DAE.
\end{abstract}

Palavras-chave: Glycine max, competição, leiteiro.

\begin{abstract}
Two experiments were carried out to evaluate the effect of different periods of control or coexistence of Euphorbia heterophylla on soybean (cv. BRS-133) grain yield at low seeding rate, at Boa Terra Farm, Buarto Centenário-PR, Brazil, during 1999-2000 growing season. The treatments for both experiments consisted of keeping the crop either with or without E. heterophylla for 5, 12, 19, 26, 33, 40, 47, 54, 61 and 68 days after emergence (DAE) and during the whole cycle. At the first weeding, for those treatments kept for increasing periods with weeds, and at harvest, for those treatments kept for increasing periods free of weed competition, $\boldsymbol{E}$. heterophylla densities and biomass were recorded. The presence of weeds caused a yield daily loss of $5.15 \mathrm{~kg} \mathrm{ha}^{-1}$, whereas their absence provided a yield daily gain of $7.27 \mathrm{~kg} \mathrm{ha}^{-1}$. Weed-crop coexistence for up to 17 DAE did not cause any negative effect on crop yield, and the maximum length of time in which weeds had to be controlled to prevent crop yield losses was 44 days after emergence. The critical period of interference was, therefore, from 17 to 44 DAE.
\end{abstract}

Key words: soybean, competition, wild poinsettia.

\section{INTRODUÇÃO}

A geração de tecnologias contribuiu para que o Brasil aumentasse sua produção de soja, passando a ocupar o segundo lugar entre os maiores produtores mundiais, sendo superado apenas pelos Estados Unidos. Em 2001, o país produziu cerca de 36 milhões de toneladas, sendo a região central do Brasil responsável por 50\% desse montante (Embrapa, 2001).

1 Recebido para publicação em 18/6/2002 e na forma revisada em 9/12/2002.

Parte das exigências para obtenção do título de Mestre em Agronomia pela primeira autora submetida ao Programa de PósGraduação em Agronomia.

2 Eng.-Agrônoma, M.S., Departamento de Agronomia da Universidade Estadual de Maringá - UEM, Av. Colombo, 5790, 87020-900 Maringá-PR, Bolsista da CAPES; ${ }^{3}$ Professor Adjunto do Departamento de Agronomia da UEM, Bolsista do CNPq. 
A busca por produtividade e economia esbarra nas interferências exercidas pelas plantas daninhas, as quais reduzem lucros e aumentam custos, tornando o produto menos competitivo no mercado. Resultados fornecidos pela Coopavel (1996) estimam que o controle de plantas daninhas na cultura da soja possa representar entre 17 e $40 \%$ do custo variável de produção. Esse percentual mostra a magnitude da importância do manejo das plantas daninhas na cultura e indica a necessidade de estudar técnicas adequadas para minimizar custo de produção e reduzir a agressão ao ambiente pelo uso de herbicidas. Blanco et al. (1973), considerando apenas as perdas relacionadas à competição direta da comunidade infestante, encontraram redução de até 95\% na produtividade da soja quando as infestantes eram constituídas principalmente por monocotiledôneas.

Uma das principais infestantes da soja no Estado do Paraná é o leiteiro (Euphorbia heterophylla). Esta espécie está distribuída pela região tropical, sendo considerada uma importante planta daninha em mais de 28 países, uma vez que causa sérios problemas a culturas anuais (Bridges et al., 1992; Willard \& Griffen, 1993). É uma planta dicotiledônea de ciclo de vida anual e pode iniciar seu florescimento em 20 a 30 dias após a emergência das plantas (Holm et al., 1997). Bridges et al. (1992) verificaram que a cultura de soja apresenta reduções de produtividade de 30 e $50 \%$, respectivamente para densidades de infestação do leiteiro de 12 e 32 plantas $\mathrm{m}^{-2}$. Karam et al. (1993) também observaram diminuições significativas de produtividade da soja, constatando que uma infestação de 42,5 plantas $\mathrm{m}^{-2}$ de E. heterophylla reduzia a produção em média $30 \%$.

Segundo Velini (1992), a competição em si pode ser definida como o recrutamento conjunto, por duas ou mais plantas, de recursos essenciais ao seu crescimento e desenvolvimento, que são limitados no ecossistema comum. Vários fatores relacionados à cultura e às plantas daninhas têm grande influência na competição, como a época, as condições edafoclimáticas e os tratos culturais.

O modelo de interferência esquematizado por Bleasdale (1960), adaptado no Brasil por Pitelli (1985), demonstra que o grau de interferência das plantas daninhas sobre a cultura agrícola é dependente de fatores ligados à cultura (espécie cultivada, cultivar ou variedade, espaçamento e densidade de semeadura), à comunidade infestante (composição específica, densidade e distribuição), ao ambiente (clima, solo e manejo da cultura) e ao período em que elas convivem.

Segundo Pitelli \& Durigan (1984), quando se estuda a interferência das plantas daninhas sobre as plantas cultivadas, é fundamental o conhecimento do Período que Antecede a Interferência (PAI), do Período Total de Prevenção de Interferência (PTPI) e do Período Crítico de Prevenção de Interferência (PCPI). O PAI é o período em que, a partir da emergência ou semeadura da cultura, esta pode conviver com a comunidade infestante antes que sua produtividade ou outra característica sejam afetadas negativamente. O PTPI é o período, a partir da emergência ou semeadura da cultura, em que esta deve ser mantida livre da presença da comunidade infestante para que sua produtividade não seja afetada negativamente. O PCPI corresponde aos limites máximos entre os dois períodos citados anteriormente e se caracteriza pelo período durante o qual é imprescindível realizar o controle.

Durante a implantação das últimas safras de soja ocorreram diversos episódios envolvendo intoxicação em plântulas de soja devido ao tratamento das sementes com fungicidas (França Neto et al., 2001a, b; Pádua et al., 2001a, b). Nesses casos, ou ainda quando a germinação das sementes é baixa ou sobrevém um período mais longo de estiagem após a semeadura, pode ser observado decréscimo significativo no estande da cultura, o que tem implicações importantes na emergência e no desenvolvimento das plantas daninhas. Embora existam referências relatando o efeito da alteração do espaçamento da soja no manejo das plantas daninhas (Braz \& Durigan, 1993; Melo et al., 2001), pouco se sabe a respeito do efeito de interferência das infestantes em condições de baixa densidade de plantas da cultura.

O objetivo do presente trabalho foi estudar os períodos de interferência de Euphorbia heterophylla na cultura da soja, cv. BRS-133, sob baixa densidade de semeadura. 


\section{MATERIAL E MÉTODOS}

Os experimentos foram instalados em campo, na Fazenda Boa Terra, no município de Quarto Centenário-PR, no mês de novembro do ano agrícola de 1999/2000. O clima da região é caracterizado como subtropical. A umidade relativa média anual é de $70 \%$ e o índice médio anual de precipitação é de $1.500 \mathrm{~mm}$. O solo da área experimental foi classificado como Podzólico Vermelho-Escuro Distrófico, textura argilosa.

Foi utilizado um cultivar recomendado para a região, o BRS-133, que é altamente produtivo e apresenta excelente ramificação lateral e boa capacidade competitiva (Brighenti et al., 2000). Possui hábito de crescimento determinado, com período juvenil longo e população recomendada de 380 mil plantas ha- ${ }^{-1}$, o que corresponde a uma densidade média de 17 plantas por metro linear no espaçamento entre linhas tradicionalmente utilizado na soja $(0,45 \mathrm{~m})$. A adubação de semeadura utilizada foi de $280 \mathrm{~kg} \mathrm{ha}^{-1}$ do formulado 0-15-20, com base nos resultados da análise de solo (Tabela 1). Antes da semeadura, entre as duas gradagens, foram aplicados também $290 \mathrm{~kg} \mathrm{ha}^{-1}$ de superfosfato simples. Essa área estava sendo cultivada há vários anos com a sucessão soja/milho.

Antes da semeadura da soja, foram distribuídas na área experimental sementes de Euphorbia heterophylla, visando a uniformização da distribuição da infestante na área. Foram distribuídos a lanço $33 \mathrm{~g}$ de sementes por parcela, tendo esta um índice de germinação de $7 \%$, objetivando o estabelecimento de uma densidade média de 25 plantas $\mathrm{m}^{-2}$. A infestação natural da área era constituída, acima de $90 \%$, por plantas dessa mesma espécie, mas em baixa densidade. Dessa forma, acima de 95\% do total da infestação da área era composto por plantas de E. heterophylla, o que justifica a análise dos dados apenas com base na interferência dessa infestante.
As sementes foram previamente inoculadas e tratadas com micronutrientes e fungicida, e a semeadura ocorreu em 23/11/1999, distribuindo-se 18 sementes por metro linear, à profundidade de $4 \mathrm{~cm}$, no espaçamento de 0,45 m entre linhas. Após a emergência e antes da instalação dos tratamentos, o estande foi corrigido e uniformizado por meio de raleio manual, de modo que a densidade de plantas fosse de 12 plantas por metro linear. Normalmente, o estande recomendado (400 mil plantas ha ${ }^{-1}$ implica uma densidade de semeadura semelhante à que foi inicialmente implantada nessa área, embora alguns produtores por vezes semeiem até 20 a 25 sementes por metro linear, no espaçamento de 0,45 m entre linhas.

Os demais tratos culturais foram realizados segundo as recomendações regionais (Embrapa, 1999). Foram feitas aplicações de inseticida piretróide para controle principalmente da lagarta da soja (Anticarsia gemmatalis) e da lagarta-rosca (Agrotis ipsilon). Essas aplicações foram necessárias em razão de ter sido um ano bastante atípico em relação ao regime pluviométrico, o que levou a ataques de pragas bastante intensos. No final do ciclo foi feita uma aplicação de fungicida, para controle de oídio (Microsphaera diffusa).

Cada unidade experimental foi constituída de dez linhas de plantas (espaçadas entre si de $0,45 \mathrm{~m}$ ) de quatro metros de comprimento, totalizando $22 \mathrm{~m}^{2}$. A área útil para as avaliações compreendia as seis linhas centrais, desprezando-se o meio metro inicial e final de cada parcela. Nas avaliações das plantas daninhas foi utilizado um quadrado de madeira com dimensões de 0,7 x 0,7 m, posicionado duas vezes, aleatoriamente, na área útil de cada parcela. Para cada período de convivência preestabelecido, as plantas daninhas presentes na área foram cortadas rente ao solo, identificadas e contadas, após o que foram levadas à estufa de circulação mecânica de ar, sendo mantidas à temperatura de $65{ }^{\circ} \mathrm{C}$ até atingir

Tabela 1 - Resultados da análise química de fertilidade do solo da área experimental. Quarto Centenário-PR, 1999/2000

\begin{tabular}{|c|c|c|c|c|c|c|c|}
\hline \multirow{2}{*}{$\begin{array}{l}\mathrm{pH} \mathrm{em} \\
\mathrm{CaCl}_{2}\end{array}$} & \multirow{2}{*}{$\frac{\mathrm{C}}{\left(\mathrm{g} \mathrm{dm}^{-3}\right)}$} & $\mathrm{Al}^{+3}$ & $\mathrm{H}+\mathrm{Al}^{+3}$ & $\mathrm{Ca}^{+2}$ & $\mathrm{Mg}^{+2}$ & K & $\mathrm{P}$ \\
\hline & & \multicolumn{4}{|c|}{$\left(\mathrm{cmol}_{\mathrm{c}} \mathrm{dm}^{-3}\right)$} & \multicolumn{2}{|c|}{$\left(\mathrm{mg} \mathrm{dm}^{-3}\right)$} \\
\hline 5,1 & 19 & 0,0 & 0,5 & 0,6 & 0,12 & 300 & 1,0 \\
\hline
\end{tabular}


peso constante. Para avaliar o efeito dos tratamentos sobre a produtividade, coletaram-se manualmente as plantas de soja da área útil de cada parcela, as quais foram posteriormente ensacadas, trilhadas e pesadas.

O delineamento experimental utilizado foi o de blocos casualizados, com quatro repetições. Os tratamentos consistiam de períodos de convivência iniciais na ausência e na presença de plantas daninhas. No primeiro experimento a cultura foi mantida livre de plantas daninhas por períodos iniciais crescentes predeterminados $(5,12,19,26,33,40,47,54$, 61,68 e ciclo todo - 118 DAE), a partir da emergência das plantas. Após esses períodos, as plantas daninhas que emergiram na parcela cresceram normalmente, não sendo mais controladas até a colheita. No segundo experimento ocorreu o inverso, ou seja, a cultura permaneceu sob interferência da comunidade infestante por períodos iniciais crescentes desde a emergência da soja $(5,12,19,26,33$, 40, 47, 54, 61, 68 e ciclo todo - 118 DAE). Após cada período de convívio, as parcelas deste experimento passavam a ser capinadas semanalmente até a colheita.

A análise estatística foi realizada separadamente para cada experimento, ambos com 11 tratamentos (períodos de convivência/ausência). Os resultados obtidos foram submetidos à análise de variância por meio do SAEG
(Gomes et al., 1990). Os dados foram estudados por meio de regressão não-linear e ajustados, para produtividade, conforme o modelo "Broken Stick" (Colwell et al., 1988). Este modelo é expresso na forma original pela equação $\mathrm{Y}=\mathrm{A}+\mathrm{B}(\mathrm{X}-\mathrm{P})-|\mathrm{X}-\mathrm{P}|$. A fórmula adaptada pode ser dada pela equação $\mathrm{Y}=\mathrm{A}-\mathrm{B}$ $(\mathrm{X}-\mathrm{P}+|\mathrm{X}-\mathrm{P}|)$. Os parâmetros da equação possuem a seguinte interpretação: A representa a produtividade máxima (patamar superior); B é a metade do ângulo formado entre a projeção do patamar máximo e a reta inclinada (ascendente ou descendente); P é o valor de X quando a curva muda bruscamente seu comportamento, ou seja, representa o período inicial ou o início do período inicial de convivência possivel; e I representa módulo.

\section{RESULTADOS E DISCUSSÃO}

Na Tabela 2 observa-se que o maior fluxo de emergência de $E$. heterophylla ocorre nos primeiros 40 dias após emergência da soja, indicando que a germinação da planta daninha concentrou-se na fase inicial da cultura. Para períodos no limpo superiores a $40 \mathrm{DAE}$, foram verificadas reduções drásticas na densidade de plantas daninhas, provavelmente em decorrência do fechamento da cultura, o qual impede, por meio do sombreamento, a germinação das infestantes e indica o momento em que a cultura passa a exercer com maior vigor o controle

Tabela 2 - Efeito de diferentes períodos de convivência de E. heterophylla com a soja sobre a produtividade da cultura e média dos dados para densidade e biomassa da planta daninha obtidos durante o ciclo da soja. Quarto Centenário-PR, $1999 / 2000$

\begin{tabular}{|c|c|c|c|c|c|c|}
\hline \multirow[t]{2}{*}{ DAE } & \multicolumn{2}{|c|}{$\begin{array}{l}\text { Produtividade } \\
\quad\left(\mathrm{kg} \mathrm{ha}^{-1}\right)\end{array}$} & \multicolumn{2}{|c|}{$\begin{array}{l}\text { Densidade de plantas daninhas } \\
\qquad\left(\mathrm{n}^{\mathrm{o}} \mathrm{m}^{-2}\right)\end{array}$} & \multicolumn{2}{|c|}{$\begin{array}{l}\text { Biomassa de plantas daninhas } \\
\qquad\left(\mathrm{g} \mathrm{m}^{-2}\right)\end{array}$} \\
\hline & Limpo & Mato & Limpo & Mato & Limpo & Mato \\
\hline $0-5$ & 2743 & 3208 & 43 & 13 & 44,5 & 5,7 \\
\hline $0-12$ & 2653 & 3115 & 46 & 22 & 48,9 & 15,1 \\
\hline $0-19$ & 2659 & 3042 & 47 & 41 & 47,9 & 35,3 \\
\hline $0-26$ & 2974 & 3279 & 44 & 47 & 46,0 & 41,2 \\
\hline $0-33$ & 3115 & 2949 & 39 & 43 & 39,4 & 45,2 \\
\hline $0-40$ & 3116 & 2672 & 21 & 44 & 38,3 & 46,5 \\
\hline $0-47$ & 3186 & 2603 & 8 & 42 & 17,8 & 47,1 \\
\hline $0-54$ & 3128 & 2863 & 3 & 48 & 4,9 & 45,9 \\
\hline $0-61$ & 3205 & 2449 & 3 & 44 & 2,1 & 60,6 \\
\hline $0-68$ & 3202 & 2539 & 4 & 42 & 2,0 & 54,8 \\
\hline 0-fim do ciclo & 3246 & 2482 & 4 & 41 & 0,5 & 51,0 \\
\hline
\end{tabular}


cultural sobre as plantas daninhas (Braz \& Durigan, 1993). Em relação aos períodos iniciais crescentes na presença de plantas daninhas (Tabela 2), observou-se que até 12 DAE no mato o acúmulo de biomassa foi relativamente baixo; no entanto, houve grande incremento na densidade de biomassa para períodos de convivência superiores a 12 dias.

Na Tabela 2 são apresentados ainda os dados de produtividade da soja, em função de períodos iniciais crescentes na presença ou ausência de plantas daninhas. Observa-se que a produtividade das parcelas mantidas no mato foi afetada em relação àquelas que foram mantidas no limpo com o aumento do período de convivência. Não há incremento na produtividade da cultura quando esta permanece no limpo por períodos maiores ou iguais a $35 \mathrm{DAE}$.

O ajuste de regressão dos dados de produtividade em função do período de convivência no limpo e no mato, pelo modelo "Broken Stick", é apresentado nas Figuras 1 e 2 . No experimento em que a cultura foi mantida por períodos iniciais crescentes na ausência de plantas daninhas (Figura 1), visou-se determinar o período a partir do qual a convivência seria possivel, ou seja, a partir de que fase do ciclo as plantas daninhas poderiam emergir e infestar a cultura sem que a produtividade fosse afetada. Na Figura 1, a curva ajustada com os dados de produção da soja indica que foi necessário um período de 44 dias de controle de plantas daninhas para que a cultura maximizasse seu potencial produtivo. Isso implica

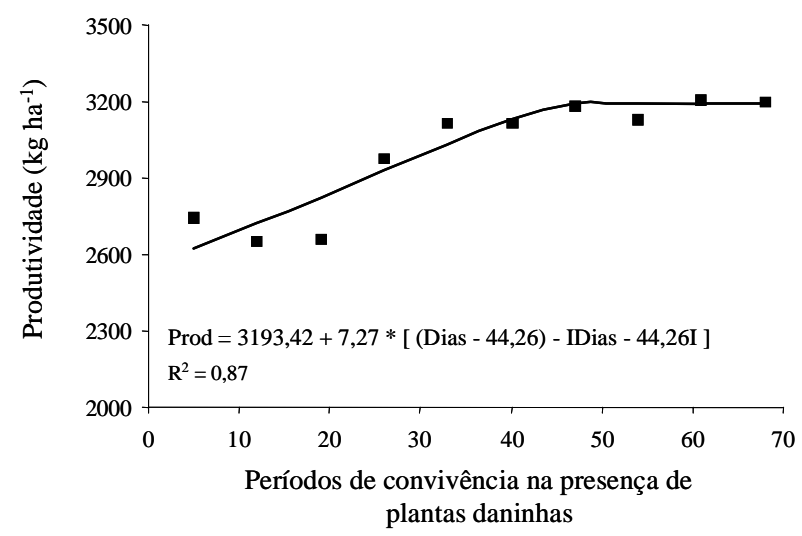

Figura 1 - Produtividade de soja em função de períodos iniciais crescentes na ausência de plantas daninhas. Quarto Centenário-PR, 1999/2000. dizer que as plantas daninhas que emergiram até os 44 DAE da soja influenciaram negativamente a produtividade e que as plantas daninhas que emergiram após este período não afetaram a produção de forma significativa. De fato, observando a Tabela 2 , foram necessários 47 dias no limpo para que as plantas daninhas apresentassem queda substancial tanto em densidade quanto em acúmulo de biomassa seca. Este período mais prolongado de necessidade de controle deve-se, provavelmente, à baixa densidade de plantas proposta no presente ensaio, o que resultou em maior demora para cobrir o solo (fechamento da soja). Vários pesquisadores (Braz \& Durigan, 1993; Carvalho \& Velini, 2001) afirmam que o sombreamento mais precoce, determinado pelo fechamento da cultura, prejudica o desenvolvimento das plantas infestantes e favorece a cultura na competição pelos fatores limitados do meio.

Para a densidade recomendada em termos de estande da cultura, a maioria dos trabalhos indica o período de 20 a 40 dias após a emergência como o intervalo necessário livre das plantas daninhas para que não ocorram decréscimos na produção (Durigan et al., 1983; Spadotto et al., 1994; Melo et al., 2001; Carvalho \& Velini, 2001). Essa variação ocorre devido a diferentes condições edafoclimáticas, níveis e espécies daninhas, tipo de solo, espaçamento, cultivar e densidade de plantas presentes na área experimental em que foram conduzidos os trabalhos (Bleasdale, 1960).

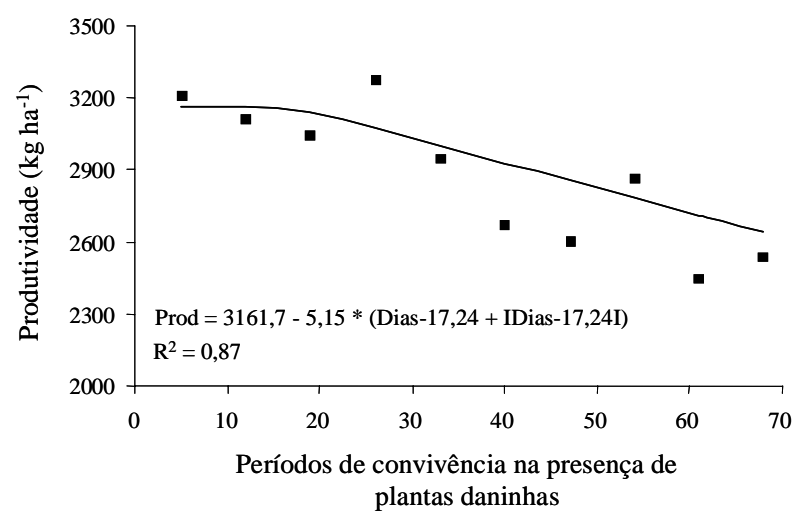

Figura 2 - Produtividade de soja em função de períodos iniciais crescentes na presença de plantas daninhas. Quarto Centenário-PR, 1999/2000.

Planta Daninha, Viçosa-MG, v.20, n.3, p.381-387, 2002 
No experimento em que a cultura foi mantida por períodos iniciais crescentes na presença de plantas daninhas, visou-se determinar o período inicial de convivência possível, ou seja, até que ponto do ciclo a interação culturacomunidade infestante não causou perdas na produtividade da soja. Para períodos iniciais crescentes na presença de plantas daninhas, a curva de dados ajustada explica $87 \%$ da variação total e indica que a produtividade só é afetada em períodos de convívio com a comunidade infestante superiores a 17 dias (Figura 2). Verifica-se que em períodos de convivio iguais ou superiores a 19 dias houve aumento considerável no acúmulo de biomassa seca da comunidade infestante (Tabela 2), revelando a estreita relação entre período de interferência e acúmulo de biomassa pelas plantas infestantes.

Diante dos resultados obtidos e utilizando o proposto por Pitelli \& Durigan (1984), concluise no presente experimento que o período total de prevenção à interferência (PTPI) foi de 44 dias e a duração do período que antecede a interferência (PAI) foi de 17 dias, ambos contados a partir da emergência da cultura. Dessa forma, fica evidente que a eliminação das plantas daninhas no período de 17 a 44 dias, dentro do período crítico de prevenção de interferência (PCPI), é necessária para que a cultura possa expressar todo o seu potencial produtivo, quando cultivada sob tal densidade de plantas. Para cada dia de ausência de E. heterophylla na cultura da soja, entre 5 e 44 dias após a emergência da cultura (DAE) houve ganho diário de produtividade de $7,27 \mathrm{~kg} \mathrm{ha}^{-1}$. No entanto, a convivência de plantas daninhas com a soja após o $17^{\circ} \mathrm{DAE}$ resultou numa perda diária de $5,15 \mathrm{~kg} \mathrm{ha}^{-1}$ em termos de produtividade de grãos.

Os dados apresentados neste trabalho indicam uma suscetibilidade mais precoce da cultura à interferência imposta por E. heterophylla, sob condições de baixo estande da soja. Sob condições usuais de densidade de plantas os períodos anteriores à interferência (PAI) da maioria dos trabalhos situam-se entre 20 e 50 dias após emergência (Rossi, 1985; Harris \& Ritter, 1987; Velini, 1989; Spadotto et al., 1994; Carvalho \& Velini, 2001).

Planta Daninha, Viçosa-MG, v.20, n.3, p.381-387, 2002

\section{LITERATURA CITADA}

BLANCO, H. G. et al. Observações sobre o período em que as plantas daninhas competem com a soja (Glycine max). O Biológico, v. 39, p. 31-35, 1973.

BLEASDALE, J. K. A. Studies on plant competition. In: HARPER, J. L. (Ed.). The biology of weeds. Oxford: Blackwell Scientific Publication, 1960. p. 133-142.

BRAZ, B. A.; DURIGAN, J. C. Redução de espaçamento e subdosagens de herbicidas aplicados em pós-emergência, para controle de plantas daninhas, em soja. In: CONGRESSO BRASILEIRO DA CIÊNCIA DAS PLANTAS DANINHAS, 19., 1993, Londrina. Resumos... Londrina: SBCPD, 1993. p. 96-97.

BRIDGES, D. C.; BRICK, B. J.; BARBAUS, J. C. Wild poinsettia (Euphorbia heterophylla) interference with peanut (Arachis hypogaea). Weed Technol., v. 40, p. 37-42, 1992.

BRIGHENTI, A. M. et al. Estudo preliminar da arquitetura de plantas de soja de diferentes cultivares de ciclo precoce e semi precoce. In: RESULTADOS DE PESQUISA DA EMBRAPA SOJA 1999. Londrina: Embrapa Soja, 2000. p. 136-137. (Embrapa Soja, Documentos, 242).

CARVALHO, F. T.; VELINI, E. D. Períodos de interferência de plantas daninhas na cultura da soja. I cultivar IAC-11. Planta Daninha, v. 19, n. 3, p. 317-322, 2001.

COLWELL, J. D.; SUHET, A. R.; RAIJ, B. van. Statistical procedures for developing general soil fertility models for variable regions. Australia: CSIRO, 1988. 68 p. (CSIRO, Division of Soils. Divisional Report, 93).

COOPAVEL. Avaliações, resultados e comentário do Show Rural Coopavel/96. Cascavel: 1996. 20 p.

(Publicação Técnica, 4).

DURIGAN, J. C. et al. Períodos de matocompetição na cultura da soja (Glycine max (L.) Merril), cultivares Santa Rosa e IAC-2. I - Efeitos sob o parâmetro da produção. Planta Daninha, v. 1, n. 2, p. 86-100, 1983.

EMPRESA BRASILEIRA DE PESQUISA AGROPECUÁRIA - EMBRAPA. Centro Nacional de Pesquisa de Soja. In: REUNIÃO DE PESQUISA DE SOJA DA REGIÃO CENTRAL DO BRASIL, 23., 2001, Londrina. Ata... Londrina: 2001. 220 p. (EMBRAPACNPSo, Documentos, 173).

EMPRESA BRASILEIRA DE PESQUISA AGROPECUÁRIA - EMBRAPA. Centro Nacional de Pesquisa de Soja. Recomendações técnicas para a cultura da soja no Paraná - 1999/2000. Londrina: 1999. 236 p. (EMBRAPA-CNPSo, Documentos, 131). 
FRANÇA NETO, J. B.; HENNING, A. A.; PÁDUA, G. P. Efeitos fitotóxicos do tratamento de sementes de soja com os fungicidas bromuconazole e Rhodiauram. II. Uberaba, MG. In: REUNIÃO DE PESQUISA DE SOJA NA REGIÃO CENTRAL DO BRASIL, 23., 2001, Londrina. Resumos... Londrina: EMBRAPA Soja, 2001a. p. 192-193.

FRANÇA NETO, J. B. et al. Sensibilidade de cultivares de soja aos efeitos fitotóxicos causados pelo tratamento de sementes com o fungicida Rhodiauram 500 SC contaminado. In: REUNIÃO DE PESQUISA DE SOJA NA REGIÃO CENTRAL DO BRASIL, 23., 2001, Londrina. Resumos... Londrina: EMBRAPA Soja, 2001b. p. 197-198.

GOMES, J. M.; GARCIA, S. L. R.; BRAGA FILHO, J. M. SAEG. Viçosa: Universidade Federal de Viçosa, 1990. $63 \mathrm{p}$.

HARRIS, T. C.; RITTER, R. L. Giant green foxtail (Setaria viridis) and fall panicum (Panicum dichotomiflorum) competition in soybeans (Glycine max). Weed Sci., v. 35, p. 663-668, 1987.

HOLM, L. et al. World weeds: natural histories and distributions. New York: Wiley, 1997. 1129 p.

KARAM, D. et al. Estudo da interferência das plantas daninhas com a cultura da soja. In: CONGRESSO BRASILEIRO DE PLANTAS DANINHAS, 19., 1993, Londrina. Resumos... Londrina: SBCPD, 1993. p. 32-33.

MELO, H. B. et al. Interferência de plantas daninhas na cultura da soja cultivada em dois espaçamentos entre linhas. Planta Daninha, v. 19, n. 2, p. 187-191, 2001.

PÁDUA, G. P.; ARANTES, N. E.; FRANÇA NETO, J. B. Reação de cultivares de soja ao tratamento com o fungicida Rhodiauram 500 SC contaminado. In: REUNIÃO DE PESQUISA DE SOJA NA REGIÃO CENTRAL DO BRASIL, 23., 2001, Londrina. Resumos... Londrina: EMBRAPA Soja. 2001a. p. 193-194.
PÁDUA, G.P.; FRANÇA NETO, J.B.; HENNING, A. A. Efeitos fitotóxicos do tratamento de sementes de soja com os fungicidas bromuconazole e Rhodiauram. I. Londrina, PR. In: REUNIÃO DE PESQUISA DE SOJA NA REGIÃO CENTRAL DO BRASIL, 23., 2001. Resumos... Londrina: Embrapa Soja. 2001b. p.195-196.

PITELLI, R. A. Interferência de plantas daninhas em culturas agrícolas. Inf. Agropec., v. 11, n. 129, p. 16-27, 1985.

PITELLI, R. A.; DURIGAN, J. C. Terminologia para períodos de controle e convivência das plantas daninhas em culturas anuais e bianuais. In: CONGRESSO

BRASILEIRO DE HERBICIDAS E PLANTAS DANINHAS, 15, 1984, Belo Horizonte. Resumos... Belo Horizonte: SBHED, 1984. p. 37.

ROSSI, C. A. Efeitos de períodos de controle e de convivência das plantas daninhas na cultura da soja. Jaboticabal/UNESP, 1985. 49 p. (Trabalho de graduação)

SPADOTTO, C. A. et al. Determinação do período crítico para prevenção da interferência de plantas daninhas na cultura da soja: uso do modelo "Broken-Stick". Planta Daninha, v. 12, n. 2, p. 59-62, 1994.

VELINI, E. D. Avaliação dos efeitos de comunidades infestantes naturais controladas por diferentes períodos sobre 0 crescimento e produtividade da cultura da soja (Glycine max). Jaboticabal: FCAV/UNESP, 1989. 115 p. Dissertação (Mestrado em Agronomia) - Universidade Estadual Paulista, 1989.

VELINI, E. D. Interferência entre plantas daninhas e cultivadas. In: KOGAN, M.; LIRA, V. J. E. Avances en manejo de malezas en la produccion agricola y florestal. Santiago del Chile: PUC/ALAM, 1992. p. 41-58.

WILLARD, T. S.; GRIFFEN, J. L. Growth and response of wild poinsettia (Euphorbia heterophylla) following foliar herbicide application. Weed Technol., v. 7, p. 190-195, 1993. 